\title{
LA APROXIMACIÓN SUBJETIVA AL CONCEPTO DE «PREVISIBILIDAD» COMO ELEMENTO DE LA GARANTÍA CRIMINAL EN DERECHO INTERNACIONAL PENAL
}

\author{
Francisco Salvador de LA Fuente CARDONA \\ Investigador Predoctoral \\ Departamento de Derecho Procesal \\ y Derecho Penal Facultad de Derecho \\ Universidad Complutense de Madrid \\ fcfuente@ucm.es \\ Margarita VALLE MARISCAL DE GANTE
Profesora Contratada Doctora
Departamento de Derecho Procesal
y Derecho Penal Facultad de Derecho
Universidad Complutense de Madrid
mvalle@ucm.es
}

RESUMEN

En el presente trabajo se plantea uno de los problemas a que se enfrenta la garantía criminal en el ordenamiento internacional penal, esto es, el tratamiento que merece la noción de «previsibilidad». En tanto la garantía criminal se habia desarrollado sobre la piedra angular que constituye la reserva de ley formal, en su incorporación al ordenamiento internacional este presupuesto se ha visto alterado y se ha tratado de suplir con el recurso a dicha noción. El objeto de controversia es hasta qué punto es admisible una aproximación subjetiva, y no solo objetiva, a un concepto de «previsibilidad» verdaderamente garantista.

Palabras clave: principio de legalidad, garantía criminal, previsibilidad, Derecho internacional penal.

\section{ABSTRACT}

By this piece of work we suggest an issue which the criminal guarantee face in International Criminal Law, that is to say, the treatment that the idea of foreseeability tends to be given. While the criminal guarantee had been developed on the basis on the cornerstone of a formal law reserve this has been altered when introduced to the core of international law bodies so this statement has been changed for the resource to such idea. A point of controversy consists of the extent to which a subjective approach would be feasible to an idea of foreseeability which truly provides a guarantee.

Keywords: principle of legality, criminal guarantee, foreseeability, international criminal law. 


\section{ZUSAMMENFASSUNG}

In der vorliegenden Arbeit wird eines der Probleme herausgestellt, denen sich die strafrechtliche Gewährleistung in der internationalen Strafrechtsordnung ausgesetzt siebt. Insofern die strafrechtliche Gewäbrleistung auf dem Vorbebalt des formalen Gesetzes rubte, war sie eingegliedert in die internationale Strafrechtsordnung. Nun wurde dieser Sachverbalt abgeändert, in dem auf die Begrifflichkeit der "Vorbersebbarkeit" zurückgegriffen wird. Das Ziel der Auseinandersetzung ist herauszustellen, bis zu welchem Punkt eine subjektive, und nicht nur objektive Herangebensweise an das Konzept der "Vorbersebbarkeit" eine wabrhafte Gewährleistung bietet.

Schlüsselwörter: Prinzip der Gesetzlichkeit, strafrechtliche Gewährleistung, Vorhersehbarkeit internationale Strafrechtsordnung.

SUMARIO: I. INTRODUCCIÓN.-II. LA GARANTÍA CRIMINAL EN DERECHO INTERNACIONAL PENAL: EL CAMBIO DE PRESUPUESTO.-III. LA NOCIÓN DE PREVISIBILIDAD ELABORADA POR EL TEDH.-IV. LA IMPORTACIÓN DE LA PREVISIBILIDAD EN LA PRÁCTICA DEL TPIY Y LA CPI.-1. La labor del Tribunal Internacional Penal para la antigua Yugoslavia (TPIY).-2. La labor de la Corte Penal Internacional (CPI).-V. CONCLUSIONES.-VI. BIBLIOGRAFÍA.

\section{INTRODUCCIÓN}

Las presentes líneas se elaboran a raíz de la comunicación presentada en el I Congreso Internacional Hispano-Brasileño sobre «Cuestiones actuales de la justicia penal» celebrado la semana del 28 de mayo de 2018 en la Facultad de Derecho de la Universidad Complutense de Madrid. En concreto, se ubicó tras la mesa sobre «Garantismo y activismo judicial» moderada por la profesora Manjón-Cabeza Olmeda y que contó con dos ponentes extraordinarios como son los profesores Vegas Torres y Díez-Picazo Giménez.

Aunque en la actualidad se habla con cierta asiduidad de activismo judicial siempre es recomendable contar con el punto de apoyo que ofrece una definición. En palabras del profesor de la Universidad de Göttingen, Ezequiel Malarino, podemos entender el activismo judicial como la «modificación judicial del derecho con el fin de actualizarlo a las necesidades sociales del momento de la aplicación» ${ }^{1}$.También el profesor Álvarez García en su estudio sobre el principio de legalidad utiliza una formula-

${ }^{1}$ E. Malarino, «Activismo judicial, punitivización y nacionalización. Tendencias antidemocráticas y antiliberales de la Corte Interamericana de Derechos Humanos», en K. Ambos, G. Elsner y E. Malarino (coords.), Sistema Interamericano de protección de los 
ción muy expresiva que se podría integrar en este fenómeno de activismo judicial, como es la existencia de una «lucha por una progresiva conquista de zonas de poder normativo» ${ }^{2}$.

En las siguientes líneas se va a tratar de arrojar luz sobre el elemento «previsibilidad» que se atribuye como exigencia de la garantía criminal, en tanto manifestación del principio de legalidad, en el ordenamiento internacional. La existencia de un sistema de fuentes formales distinto de aquel sobre el que se asienta la construcción de la garantía criminal y el estado del Derecho internacional penal, todavía en desarrollo, han propiciado un espacio donde los jueces han ostentado una verdadera labor de impulso y, en la que podemos adelantar, ha existo cierto activismo.

En primer lugar, recordaremos las notas que originariamente caracterizan a la garantía criminal y lo pondremos en relación con su incorporación al ordenamiento internacional. Numerosos textos internacionales tanto de protección de derechos humanos como de Derecho internacional penal exigen su respeto, pero, ahora bien, en su aplicación hay que tener en cuenta que el presupuesto del que se partía en los ordenamientos internos ha cambiado: ya no hay una reserva absoluta de ley formal. En segundo lugar, y precisamente para superar las dificultades que este escenario deja abiertas, un tribunal autorizado como es el Tribunal Europeo de Derechos Humanos (TEDH) ha introducido el requisito de la «previsibilidad», aunque con ciertas vacilaciones; noción que ha fertilizado la práctica del resto de tribunales internacionales tanto de derechos humanos como penales. En tercer lugar, y desde la perspectiva del Derecho internacional penal como disciplina de encuentro, lo anterior va a tener que ser conjugado para atribuir responsabilidad penal individual. ¿Cómo ha sido elaborado? ¿Cuál ha sido la interpretación judicial? ¿Se ha satisfecho el originario contenido garantista? Son algunas de las preguntas que trataremos de responder.

\footnotetext{
derechos humanos y derecho penal internacional, Montevideo, Fundación Konrad-Adenauer, 2010, p. 29.

2 F. J. Állvarez García, Sobre el principio de legalidad, Valencia, Tirant lo Blanch, 2009, pp. 216 y ss., acusación que dirige al Tribunal Supremo español al hilo de la interpretación de la atenuante analógica por dilaciones indebidas.
} 


\section{LA INCORPORACIÓN DE LA GARANTÍA CRIMINAL EN DERECHO INTERNACIONAL PENAL: EL CAMBIO DE PRESUPUESTO}

Cuando pensamos en la hoy denominada «garantía criminal» nos estamos refiriendo a una de las manifestaciones del principio de legalidad penal; construcción que heredamos del nuevo sistema de legitimidades impulsado por la filosofía ilustrada y que, «con una esperanza casi reveladora en la ley», los revolucionarios franceses plasmaron por primera vez en la Declaración de los Derechos del Hombre y del Ciudadano de $1789^{3}$, en cuyo sistema de separación de poderes hunde sus raíces nuestro Estado democrático de Derecho. Es más, es la interiorización de los principales atributos de este principio, como criterio inherente a la justicia de las condenas, lo que va a provocar su recepción en el ordenamiento internacional tras la Segunda Guerra Mundial tanto a través de la entonces in status nascendi, disciplina del Derecho internacional de los derechos humanos, como en el ámbito del Derecho internacional penal con la experiencia de los denominados Juicios de Núremberg.

Antes de introducirnos en la práctica internacional, que es el campo examinado en este trabajo, debemos volver nuestra atención, siquiera sumariamente y precisamente por el mencionado origen continental del principio de legalidad penal, al significado y construcción sobre el que se vertebra. La naturaleza de derecho fundamental que nuestras Constituciones atribuyen a la legalidad penal ${ }^{4}$ y su relación y límite con la función atribuida en nuestro sistema al Derecho penal justifican la necesidad de dedi-

3 En concreto en los arts. 7 y 8. Como recoge, en el que fuera su discurso de ingreso a la Real Academia de la Lengua Española, E. GarCía DE EnTERRía, La lengua de los derechos. La formación del Derecho público europeo tras la Revolución francesa, Madrid, Alianza Universidad, 1994, p. 161, «la predeterminación legal de las conductas punibles creará un ámbito social enteramente secularizado de seguridad jurídica, no coartada ahora por el temor de irritar en cualquier circunstancia al gobernante o al juez o de enfrentar los criterios morales de cualquier autoridad social, religiosa o política»; también C. LAMARCA PÉREZ, «Principio de legalidad penal», Eunomía, núm. 1 (2011), p. 157, señala que «cabe considerar el principio de legalidad como un «hijo de la Ilustración» que surge en los orígenes ideológicos del Derecho penal moderno como la primera consecuencia del fundamento contractual del ius puniendi, pero también, y al mismo tiempo, como el primero de sus límites».

${ }^{4}$ E. GarCia DE ENTERRÍA, «El principio de legalidad, estado material de Derecho y facultades interpretativas y constructivas de la jurisprudencia en la Constitución», Revista Española de Derecho Constitucional, núm. 10 (1984), pp. 11-13, señala que el principio de legalidad de los delitos se regula en el art. $25 \mathrm{CE}$, el cual es manifestación de la más general cláusula de «Estado de Derecho» previsto en el art. 9.3 CE, que recoge «una técnica deter- 
car un espacio a la garantía criminal ${ }^{5}$ y a las dificultades a que se enfrenta esta construcción en el ordenamiento internacional, reservando para otra ocasión el tratamiento, no menos importante, de la garantía penal ${ }^{6}$.

La garantía criminal o nullum crimen sine lege, aforismo acuñado por Feuerbach, observa el cómo se ha operado la regulación del comportamiento típico, de la conducta que se considera generadora de un desvalor merecedor de tutela penal, y, simultáneamente, condiciona la función de aplicación e interpretación que lleva a cabo el poder judicial. El contenido de la garantía criminal, en ordenamientos como el español, está integrado por un aspecto formal que se dirige tanto al legislador, a través de la reserva de $l e y^{7}$, como al aplicador, mediante el principio de tipicidad ${ }^{8} \mathrm{y}$

minada de organizar la vida colectiva, no por los hombres, los cuales, en cuanto ejerzan autoridad, solo podrán exigir obediencia «en nombre de la ley»».

${ }^{5}$ Sobre la garantía criminal citaremos principalmente doctrina española. En lengua inglesa se pueden ver los recientes trabajos de M. Timmerman, Legality in Europe. On the principe nullum crimen, nulla poena sine lege in EU law and under the ECHR, Cambridge, Intersentia, 2018; T. RAUTER, Judicial practice, customary international criminal law and nullum crimen sine lege, Salzburg, Springer, 2017.

${ }^{6}$ En el plano internacional la garantía penal es incluso más limitada, S. D'ASCOLI, Sentencing in International Criminal Law. The UN ad hoc Tribunals and Future Perspectives for the ICC, Oxford, Hart Publishing, 2011, p. 17, «in a number of international buman rights instruments... quite often nothing is said concerning the legality of penalties and the fact that they should be fixed or determined beforehand, and contained in "written" law», exigiéndose como lex praevia pero no lex certa.

${ }^{7}$ No siendo este el lugar para detenernos en profundidad sobre las cuestiones que deja abiertas la formulación de la reserva de ley en el ordenamiento español, sí debemos señalar dos ideas. En primer lugar, la doctrina mayoritaria entiende que las leyes penales afectan siempre al desarrollo de los derechos fundamentales y de las libertades públicas regulados en la Sección primera del Capítulo II del Título I de la CE y, por tanto, conectan el término «legislación vigente» del art. 25.1 CE con el art. $81 \mathrm{CE}$ que recoge la reserva de ley orgánica para el desarrollo de los mismos. Sin embargo, como destaca J. C. CARBonell Mateu, Derecho penal: concepto y principios constitucionales, 2. ${ }^{a}$ ed., Valencia, Tirant lo Blanch, 1996, pp. 112-115, el Tribunal Constitucional solo ha reconocido parcialmente esta tesis y ha distinguido entre los preceptos penales que prevén penas privativas de libertad y aquellos otros que tan solo prevén penas pecuniarias o de otro tipo, lo que olvida la existencia del arresto sustitutorio por impago de multa. Además, critica que el TC ponga el acento en la consecuencia jurídica (pena) y no en la tipificación que, a su juicio, se ha de entender como la reducción del principio general de libertad; en contra de la reserva absoluta de ley orgánica, C. LAMARCA PÉREZ, «Legalidad penal y reserva de ley en la Constitución española», Revista Española de Derecho Constitucional, núm. 20 (1987), pp. 125 y ss. En segundo lugar, la dificultad de recoger en la ley todos los comportamientos que se consideran dignos de atención penal ha llevado a la remisión normativa, sobre todo a través de la figura de las leyes penales en blanco, sobre ello ver el reciente trabajo de G. GONZÁLEZ AguADELO, «El principio de reserva de ley penal y las leyes penales en blanco. Una reflexión sobre el derecho fundamental a la legalidad penal», RGDP, núm. 28 (2017), pp. 30 y ss., en particular sobre la STC 101/2012.

${ }^{8}$ No es pacífico si el principio de taxatividad y el de tipicidad son dos calificativos para una misma exigencia o si, por el contrario, el principio de taxatividad sería el dirigido 
la prohibición de analogía'; un aspecto material, constituido por el principio de taxatividad ${ }^{10}$, y un fin u objetivo, al que sin perder su autonomía de manera decisiva coadyuvan los anteriores, que constituye a su vez una de las garantías más características del principio de legalidad como es la irretroactividad de la ley penal ${ }^{11}$ y su reverso, la exigencia de ley previa.

El punto de arranque de este razonamiento, que encierra una auténtica evaluación de las normas penales, es la reserva de ley, la existencia de una norma escrita. Todo el despliegue argumental que se realiza posteriormente pone el foco de atención, opera, principalmente, desde el texto de la norma. Así, nuestro Tribunal Constitucional cuando examina la conformidad con este principio de la norma penal en abstracto (las menos) o de la interpretación jurisprudencial (las más, por la vía del recurso de amparo) ${ }^{12}$ tomará siempre el texto de aquella como punto de partida.

al legislador y el de tipicidad a los tribunales. Parece a favor de la primera concepción R. DE Vicente MarTíneZ, El principio de legalidad penal, Valencia, Tirant lo Blanch, 2004, p. 130; entiende el principio de tipicidad como «vinculación del juez a la ley penal», J. A. LASCURAín SÁNCHEZ, «La protección multinivel de la garantía de tipicidad penal», en M. PÉREZ MANZANO y J. A. LASCURAín SÁnCHEZ, La tutela multinivel del principio de legalidad penal, Madrid, Marcial Pons, 2016, p. 120, optando por esta diferenciación a los efectos de nuestro trabajo.

9 S. HuerTA TOCILDO, «El derecho fundamental a la legalidad penal», Revista Española de Derecho Constitucional, núm. 39 (1993), p. 108, citando a GRÜNWALD y MAYER recoge esta distinción. Aunque la prohibición de retroactividad se entiende como contenido formal, a los efectos de este trabajo se presenta en último lugar.

10 J. C. Carbonell Mateu, Derecho penal: concepto y principios..., op. cit., p. 127, el principio de taxatividad exige que el legislador emplee una técnica de creación, de elaboración de la norma, en virtud de la cual sea posible, con una simple lectura del precepto, conocer hasta dónde llega este... dónde comienza el Derecho».

${ }^{11}$ Señala R. DE Vicente MarTíneZ, El principio de legalidad penal, op. cit., p. 30, que «el principio de la irretroactividad de la ley penal desfavorable encuentra un fundamento jurídico penal en la teoría de la coacción psicológica de FEUERBACH quien no solo ideó la formulación latina del principio de legalidad, sino que le añadió una fundamentación autónoma partiendo de la teoría de la pena»; M. SCOLETTA, «El principio de legalidad europeo», en L. Díez-Picazo y A. Nieto Martín (coords.), Derechos fundamentales en el Derecho penal europeo, Madrid, Civitas, 2010, p. 252, indica que «la libertad individual se tutela en cuanto posibilidad de orientar racionalmente los propios comportamientos vitales conformes a las valoraciones de desvalor expresadas por el ordenamiento jurídico vigente (la garantía de «elección libre de acción», a la cual ha hecho referencia el Tribunal constitucional italiano)».

${ }_{12}$ Esta práctica del Tribunal Constitucional español también es observada en países de nuestro entorno como Alemania, donde el recientemente fallecido profesor K. TIEDEMANN, «Constitución y Derecho penal [Traducción: Luis Arroyo Zapatero]», Revista Española de Derecho Constitucional, núm. 33 (1991), p. 163, indicaba que «solo respecto de la probibición de la analogía el Tribunal Constitucional ha llegado a poner seriamente en cuestión la constitucionalidad de un precepto... Tras esta divergencia se oculta la explicación de que el mandato de determinación [taxatividad] de las normas penales es un mandato dirigido al legislador, mientras que la prohibición de analogía se dirige a los jueces, y...al primero se le concede un amplio margen de arbitrio en la configuración de la ley». 
Es aquí donde reside la clave para comprender el origen del reto a que se enfrenta el pretendido principio de legalidad en Derecho internacional penal. Y ello porque, tanto en los textos internacionales de protección de derechos humanos y en sus órganos de interpretación y aplicación, cuya doctrina permea en la práctica de los tribunales penales internacionales, como en los propios sistemas de justicia penal internacional que se han ido desarrollando, se aspira a conseguir el resultado último atribuido al principio de legalidad penal, esto es, la existencia de una ley previa que evite su aplicación retroactiva, sin pasar, necesariamente, por el «peaje» formal y material que originariamente se atribuye a la legalidad penal, cuyo anclaje se hunde en un sistema de fuentes cuyo presupuesto es la reserva de ley formal. Llegados a este punto, podemos adelantar que, como destaca Scoletta, «la ampliación de las posibles fuentes de producción del Derecho penal condiciona la concreta fisonomía de los corolarios del principio de legalidad $\gg^{13} \mathrm{y}$, añadimos, se convierte en terreno fértil para introducir tanto consideraciones de justicia sustantiva como reformulaciones en el esquema de análisis.

Que con carácter general el Estado haya sido el sujeto principal del ordenamiento internacional ha dado lugar a un sistema propio de fuentes formales, pues la fuente material es precisamente la voluntad de esos sujetos estatales, integrado por normas escritas (tratados internacionales) y normas no escritas (costumbre y principios generales). Si queremos hacer un paralelismo con el ordenamiento interno, aquí el constituyente es el Estado y es su voluntad, que puede manifestarse por diversos cauces, la que crea Derecho. De lo anterior se deriva, en cuanto al Derecho internacional penal y al principio de legalidad penal, que en tanto así ha sido querido por los Estados, en aquellos casos en que se dirima la responsabilidad penal internacional de un individuo se aplique un sistema de fuentes formales, unos medios normativos, que en buena medida se comparte con el resto del ordenamiento internacional, y ello aunque nos encontramos ante un nuevo destinatario: el individuo ${ }^{14}$.

${ }^{13}$ M. ScoletTA, «El principio de legalidad europeo», op. cit., p. 262.

${ }^{14}$ M. BOHLANDER, «Volver a Radbruch. La necesidad de retomar de raíz el diálogo entre common law y Derecho continental, en atención al ejemplo de la justicia penal internacional», en E. Ferrer Mac-Gregor y A. Herrera García, Diálogo jurisprudencial en derechos humanos entre Tribunales Constitucionales y Cortes Internacionales, Valencia, Tirant lo Blanch, 2013, p. 1139, al hilo de los problemas de comprensión entre common law y civil law y de la necesidad de retomar los niveles más elementales de discusión (y conocimiento), señala en cuanto a la justicia penal internacional que «el Derecho internacional público, que se apoya en gran medida, en el ámbito del Derecho penal, en la costumbre..., toma en con- 
Esto ha provocado que el esquema de la garantía criminal, como manifestación del principio de legalidad penal cuyo presupuesto es la ley formal, por el momento no sea trasladable en los mismos términos a los sistemas de justicia internacional penal. Inmediatamente nos surge la siguiente pregunta, ¿sería posible llegar al mismo resultado garantista por otro camino? Antes de buscar la respuesta a esta pregunta en la práctica de los principales tribunales penales internacionales, sí podemos adelantar que, al menos, se ha intentado ${ }^{15}$. Con todo, como es el sistema de fuentes formales el que condiciona la consecución de la pretendida garantía criminal en el ordenamiento internacional, es menester que primero recordemos cuál es ese sistema de fuentes sobre el que los tribunales han llevado a cabo su labor para, posteriormente, analizar esta.

El Derecho internacional penal es, en lo que ahora interesa, un «cuerpo de normas internacionales» destinado a proscribir aquellos comportamientos que se consideran universalmente como generadores de un mayor desvalor (crímenes internacionales) y a hacer penalmente responsables a sus autores» ${ }^{16}$. Es por ello que, en tanto sector del Derecho internacional público, podemos encontrar como cláusula informadora de su sistema de fuentes formales el art. 38.1 del Estatuto del Tribunal Internacional de Justicia (ETIJ), sin perjuicio de lo previsto en el art. 21 del Estatuto de la Corte Penal Internacional (ECPI). Convenciones internacionales, costumbre internacional y principios generales del Derecho como distintos modos

sideración una pléyade de factores adicionales que tienden a chocar con las aproximaciones de ambos sistemas domésticos [common law y civil law], basadas en el juicio justo y en la criminalización mínima: la práctica de los Estados y la cortesía internacionales. Ambos factores están en una innata tensión...», tensión que puede encontrar una de sus manifestaciones en la aplicación del sistema de fuentes formales a un nuevo destinatario.

15 Baste recordar, como veremos más adelante, el comentario del Secretario General de la ONU al Estatuto del Tribunal Penal Internacional para la antigua Yugoslavia o el Estatuto de la Corte Penal Internacional.

${ }^{16}$ Esta definición está tomada de A. CASSESE, International Criminal Law, 3. a ed., Oxford, Oxford University Press, 2013, p. 3, las primeras serían «normas sustantivas» que incluirían, además de las conductas prohibidas y sus consecuencias, otras reglas con capacidad para modular la responsabilidad del individuo; el segundo grupo se refiere a las «normas procesales»; M. C. BAssiouni, Introduction to International Criminal Law, 2. ${ }^{a}$ ed., Boston, Martinus Nijhoff Publishers, 2014, p. 1, comienza destacando las particularidades de tal disciplina al indicar que: «International Criminal Law (ICL) is a complex legal discipline consisting of several components bound by their functional relationship in the pursuit of value-oriented goals». Más adelante, reconoce que la coherencia doctrinal y metodológica es insuficiente pero afirma que, sin embargo, «the different components that make up ICL constitute a functional whole»; también, K. AmBos, «La construcción de una parte general del Derecho penal internacional», Revista Penal, núm. 17 (2006), p. 5, define el Derecho internacional penal como «el conjunto de todas las normas de Derecho internacional que establecen consecuencias jurídico-penales». 
de generar obligaciones adquieren matices propios en el Derecho internacional penal. Frente al Derecho internacional público general u otras ramas del mismo, como el Derecho internacional de derechos humanos (DIDH), que tiene como destinatario principal a los Estados, el Derecho internacional penal centra su regulación en la conducta de las personas y ello implicaría una mayor exigencia de claridad y precisión ${ }^{17}$, lo que desgraciadamente la práctica no siempre ha corroborado.

Por su parte, la Corte Penal Internacional (CPI) constituye en estos momentos el principal y más sofisticado sistema de justicia penal internacional. En este sentido, y a diferencia del Estatuto del Tribunal Penal Internacional para la antigua Yugoslavia (TPIY) o del Estatuto de Londres de 1945, en el art. 21 ECPI se recoge el «Derecho aplicable» ${ }^{18}$, esto es, un sistema de fuentes formales propio de la Corte que, a los efectos del principio de legalidad, nos interesa porque limita la discrecionalidad de los jueces y quiebra la igualdad entre fuentes propia del art. 38.1 del Estatuto de la Corte Internacional de Justicia (ECIJ), pareciendo sentar una primacía de las fuentes «propias» del sistema de la CPI que, a su vez, resultan ser las que tienen carácter escrito ${ }^{19}$.

¿Encerraría el art. 21 ECPI una reserva de ley que pudiera servir para trasladar el razonamiento originario de la garantía criminal? Lamentablemente, no. Ni el Derecho internacional penal, en general, ni el sistema creado por el Estatuto de Roma incorporan la garantía criminal en los términos que originariamente se le atribuye, es decir, hay un cambio de presupuesto que lleva a hablar en esta disciplina de «principio de juridicidad» ${ }^{20}$ o nullum crimen sine iure ${ }^{21}$.

17 A. CASSESE, International Criminal Law, 2. ${ }^{a}$ ed., Valencia, Tirant lo Blanch, 2011, p. 8, llegando a afirmar que «the inherent requirements underlying ICL (not less than any national body of criminal law) may therefore collide with the traditional characteristics of PIL».

18 Por todos, W. SCHABAS, «Article 21. Applicable Law», en The International Criminal Court: A commentary on the Rome Statute, Oxford, Oxford University Press, 2010.

19 Esto también se refleja en la interpretación del Derecho (tan acusada de ser «creativa), así L. GROVER, «A call to arms: fundamental dilemmas confronting the interpretation of crimes in the Rome Statute of the International Criminal Court», The European Journal of International Law, vol. 21 (3) (2010), p. 557 y ss., señala la primacía de las normas escritas y que la consideración del principio de legalidad como criterio interpretativo de los crímenes «would require the textual approach to prevail over competing intent as well as object and purpose based approaches».

20 A. GIL GIL, «La excepción al principio de legalidad del número 2 del artículo 7 del Convenio Europeo de Derechos Humanos», ADPCP, vol. LXIII (2010), p. 145, aunque referido al CEDH afirma que consagra un ««principio de juridicidad» en el que la reserva absoluta de ley formal se sustituye por una exigencia de previsibilidad».

${ }^{21}$ H. Olásolo Alonso, Introducción al Derecho Internacional penal, Valencia, Tirant lo Blanch, 2015, p. 81. 
Ahora bien, el condicionamiento que ejerce el sistema del art. 21 ECPI en la identificación y aplicación del Derecho, junto con la propia regulación de la garantía criminal en los arts. 22 y 24, el reconocimiento en el propio ECPI de otros principios, como el error de Derecho, así como la prudencia judicial ante algunas críticas recibidas por los tribunales ad hoc, no es baladí. Como veremos, determinará el modo en que los jueces de la Corte tratarán de aproximarse a la garantía criminal, pudiendo corregir, al menos parcialmente, los signos de justicia sustantiva y la «subjetivación» a que, como veremos, empuja el previamente señalado esquema de fuentes formales del Derecho internacional penal.

\section{EL ORIGEN DE LA NOCIÓN DE «PREVISIBILIDAD»: ELABORACIÓN DEL TEDH}

En el análisis jurisprudencial del principio de legalidad penal y, en concreto, de la garantía criminal, debemos tener presente la íntima relación entre dos disciplinas de Derecho internacional público cuyo auge siguió a los juicios de Núremberg. Estas son el Derecho internacional penal y el Derecho internacional de los derechos humanos ${ }^{22}$. Y es que, como ha señalado Chinchón Álvarez, «aun dentro del ordenamiento jurídico internacional, el DIDH presenta una especificidad [...] se centra en cuestiones entre los Estados y los seres humanos bajo su jurisdicción» ${ }^{23}$. Lo ante-

\footnotetext{
${ }^{22}$ Sobre la distinción entre DIDH y Derecho internacional penal y entre responsabilidad internacional del Estado y del individuo, ver J. Chinchón Álvarez, Derecho Internacional y Transiciones a la Democracia, Sevilla, Ediciones Parthenon, 2007, pp. 41 y ss.; ÍD., «La responsabilidad internacional penal del individuo: un gigante con pies de barro», Revista de Ciencias Jurídicas, núm. 108 (2005), p. 41, donde sostiene que el foco del Derecho internacional penal en el individuo como sujeto activo es «aparente» y que realmente sería «elemento pasivo de Derecho» que identifica con la capacidad de que la conducta del particular pueda constituir en sí misma un acto internacionalmente ilícito del que se derivaría su responsabilidad; citando a Miaja de la Muela, M. Castillo Daudí y S. Salinas Alcega, Responsabilidad penal del individuo ante los tribunales internacionales, Valencia, Tirant lo Blanch, 2007, p. 13, indican que «el Derecho internacional sigue dominado por lo que Verdross denominó «mediatización del hombre», porque solo a través del Estado, destinatario directo de las normas internacionales, pueden estas llegar a afectarlo»; aunque centra su trabajo en un examen ciertamente crítico de la noción de «crimen internacional» prevista el art. 19 del Proyecto de la CDI de 1996, L. Pérez-PrAt Durbán, «La responsabilidad internacional, ¿crímenes de Estados y/o de individuos?», AFDUAM, núm. 4 (2000), p. 222, incide en que «ambas [responsabilidades internacionales] gozan de una evidente autonomía, incluso en los casos en los que se trate de los mismos actos ilícitos, de los mismos crímenes». p. 231.

${ }^{23}$ J. ChInchón Álvarez, Derecho Internacional y Transiciones a la Democracia, op. cit,
} 
rior va a dar lugar a que estas dos disciplinas conozcan del principio de legalidad penal, en tanto hoy derecho humano dirigido a los Estados en la impartición de justicia y, simultáneamente, principio informador de los sistemas de justicia internacional penal cuya observancia se entiende como conditio para afirmar la justicia de una condena.

En la medida en que los tribunales internacionales que se han creado como garantes del respeto a ambas disciplinas han llevado a cabo una aproximación al principio de legalidad penal y ha habido un proceso de recepción e intercambio de categorías y razonamientos ${ }^{24}$, se explica que, en un primer momento, sea necesario analizar la práctica del principal sistema regional de protección de derechos humanos, esto es, el construido por la organización internacional Consejo de Europa en torno al conocido como Convenio Europeo de Derechos Humanos (CEDH). El diálogo entre el autorizado Tribunal Europeo de Derechos Humanos (TEDH) y los tribunales penales internacionales ha sido una realidad, entre otros ámbitos, en cuanto a la garantía criminal.

El CEDH ${ }^{25}$ recoge en su art. 7 el principio de legalidad penal otorgándole un carácter preferente, dado que el art. 15.2 «no autoriza» ninguna derogación del mismo, así como del derecho a la vida (art. 2), la prohibición de tortura (art. 3) y la prohibición de esclavitud o servidumbre (art. 4, primer párrafo) en caso de «guerra o de otro peligro público que amenace la vida de la nación». Por ello, Carrillo Salcedo afirma que estos derechos, como el derecho a la legalidad penal, suponen «la precisión de un núcleo duro de derechos humanos que [...] están protegidos por normas imperativas que dan testimonio de la existencia de un orden público europeo en materia de derechos humanos» ${ }^{26}$.

${ }^{24}$ Sobre este fenómeno también calificado como de fertilización cruzada, J. GARCÍA RocA, «El diálogo entre el Tribunal Europeo de Derechos Humanos, los Tribunales Constitucionales y otros órganos jurisdiccionales en el espacio convencional europeo», en E. Ferrer Mac-Gregor y A. Herrera García (coords.), Diálogo jurisprudencial en derechos bumanos entre tribunales constitucionales y cortes internacionales, Valencia, Tirant lo Blanch, 2013, p. 223, advierte que «la doctrina del diálogo judicial, de origen anglosajón, mezcla ingredientes filosóficos, políticos y sociológicos y, en la medida en que no es una elaboración exclusivamente jurídica, ni ciertamente una categoría precisa, puede producir el serio riesgo de un debilitamiento metodológico... una especie de cajón de sastre».

${ }^{25}$ Sobre la naturaleza y dimensión constitucional del CEDH se puede ver J. A. CARRILLo SalCEDo, El Convenio Europeo de Derechos Humanos, Madrid, Tecnos, 2003, pp. 11-48; más reciente, y en particular sobre la reforma introducida por el Protocolo 14, J. CASADEvall, El Convenio Europeo de Derechos Humanos, el Tribunal de Estrasburgo y su Jurisprudencia, Valencia, Tirant lo Blanch, 2012, pp. 127 y ss.

26 J. A. Carrillo Salcedo, El Convenio Europeo de Derechos Humanos, op. cit., p. 317. 
Con carácter general, a la hora de analizar el art. 7 CEDH debemos hacer las siguientes precisiones. El art. 7.1, primer inciso, contiene la garantía criminal objeto de nuestra atención y su segundo inciso recoge la garantía penal al señalar que «no podrá ser impuesta una pena más grave que la aplicable en el momento en que la infracción haya sido cometida». Por su parte, genera cierta controversia el art. 7.2 o «cláusula Núremberg», introducido ante la preocupación de que la labor del Tribunal Militar Internacional (TMI) de Núremberg quedase deslegitimada. Un sector de la doctrina considera que es una «excepción» al principio de legalidad penal ${ }^{27}$; postura que a su vez parece ser corroborada por los términos en que la Corte se ha referido a dicha disposición ${ }^{28}$. No obstante, como señalamos más arriba, algunas voces autorizadas como el profesor Cassese han querido ver en el art. 7.2 una ampliación de las fuentes previstas en el art. 7.129, lo cual es cuestionado porque dejaría sin un contenido real al segundo apartado, en tanto la expresión «Derecho internacional» (art. 7.1) ya nos remitiría al art. $38.1 \mathrm{ECIJ}^{30}$.

Sentado lo anterior, dirigimos nuestra atención a la garantía criminal. El art. 7.1, primer inciso, establece que «nadie podrá ser condenado por

27 A. GIL GIL, «La excepción al principio de legalidad», op. cit., p. 157, concluye que «el TEDH está aplicando en los casos de crímenes internacionales un derecho excepcional sin reconocerlo y sin querer aludir expresamente a la excepción del art. 7.2»; S. HUERTA TOCILDO, «El contenido debilitado del principio europeo de legalidad penal (art. 7 CEDH y art. 4 P7), en J. García Roca y P. Santolaya (coords.), La Europa de los Derechos: el Convenio Europeo de Derechos Humanos, Madrid, Centro de Estudios Políticos y Constitucionales, 2009 , p. 519, indica que «la existencia de sistemas políticos de corte totalitario... ha llevado a plantear a nivel internacional la necesidad de excepcionar dicha prohibición [de retroactividad] en el caso de hechos cometidos al amparo de normativas nacionales que, pese a su aparente "legalidad", fueran por completo opuestas a los principios elementales de justicia y de protección internacional de los derechos humanos» [cursivas añadidas].

${ }^{28}$ STEDH de 17 de mayo de 2010 (Kononov v. Latvia), par. 186 «the Court considers it relevant to recall that the travaux préparatoires to the Convention indicate that the purpose of the second paragraph of article 7 was to specify that article 7 did not affect law which, in the wholly exceptional circumstances at the end of the Second World War, were passed to punish, inter alia, war crimes so that article 7 does not in any way aim to pass legal or moral judgment on those laws».

29 A. CASSESE, «Balancing the prosecution of crimes against Humanity and Non-retroactivity of Criminal Law. The Kolk and Kislyiy v. Estonia Case before the ECHR», Journal of International Criminal Justice, vol. 4 (2006), p. 415, sostiene que el propósito del art. 7.2 «is instead to ensure that conduct which is not criminalized by either treaty or customary rules, may nevertheless be held criminal and therefore punishable by the virtue of general principles of law recognized by the whole international community».

${ }_{30}$ T. MarinieLLo, «The "Nuremberg Clause" and Beyond: Legality Principle and Sources of International Criminal Law in the European Court's Jurisprudence», Nordic Journal of International Law, vol. 82 (2013), p. 227. 
una acción o una omisión que, en el momento en que haya sido cometida, no constituya una infracción según el Derecho nacional o internacional». Así, lo primero que merece ser destacado es la referencia al Derecho nacional e internacional, esto es, el punto de partida del TEDH para analizar la garantía criminal es el amplio conjunto de fuentes formales que abarca el Derecho internacional público en los términos señalados más arriba, comprendiendo tratados internacionales, costumbre y principios generales ${ }^{31}$, y, por otro lado, los Derechos nacionales, que dado el numeroso grupo de Estados parte abarca tanto países del common law como del civil law. Esto se traduce en que «Derecho» a la luz del Convenio es tanto el de origen legislativo como el de origen jurisprudencial.

Como manifestaciones de la garantía criminal, el TEDH señala en reiteradas ocasiones: i) la claridad en la definición (lex certa) ${ }^{32}$; ii) la prohibición de construcción extensiva de los tipos, en particular la analogía (lex stricta) ${ }^{33}$, y, en consecuencia, iii) la prohibición de aplicación retroactiva desfavorable (lex praevia) ${ }^{34}$. Ahora bien, en tanto el esquema de fuentes carece de una reserva de ley formal (lex scripta) y la referencia a otros criterios utilizados por el TEDH tiene un carácter secundario ${ }^{35}$, la verdadera unidad de medida a través de la cual se va a valorar la conformidad de la condena con la garantía criminal así entendida es la denomina$\mathrm{da}$ «previsibilidad» ${ }^{36}$ como condición cualitativa del Derecho aplicado, sea cual fuere su origen.

31 Por todas, STEDH de 12 de febrero de 2008 (Kafkaris v. Cyprus), par. 139, recoge que "the Court has always understood the term "law" in its "substantive" sense, not its "formal" one. It has thus included both enactmenst of lower rank than statutes and unwritten law. In sum, the "law" is the provision in forcé as the competent courts have interpreted it».

32 Por todas, STEDH de 23 de julio de 2013 (Khodorkovskiy and Lebedev v. Russia), par. 779, «it follows that the offences and the relevant penalties must be clearly defined in law».

33 STEDH de 25 de septiembre de 2009 (Liivik v. Estonia), par. 92, «it also lays down the principle that the criminal law must not be extensively construed to an accused's detriment, for instance by analogy».

34 STEDH de 22 de junio de 2000 (Coëme and others v. Belgium), par. 145, indica que «it probibits in particular extending the scope of existing offences to acts which previously were not criminal offences».

${ }_{35}$ M. Timmerman, Legality in Europe, op. cit., pp. 82 y ss., señala que otros criterios utilizados por el TEDH para valorar la conformidad de la condena con el art. 7 son la «esencia del delito» y «la grave naturaleza del delito», cuya utilización o bien tiene un carácter limitado o bien desaconseja porque evocaría una idea de justicia sustantiva frente a la legalidad.

36 Ibid., p. 86, reconoce el contenido limitado de la noción «accesibilidad» y entiende que para comprobar el respeto de los tres sub-principios (lex certa, lex stricta y lex praevia) «the foreseeability requirement... has been the most distinctive criterion». 
Nos preguntábamos más arriba si era posible, teniendo en cuenta que el presupuesto de las fuentes formales había sido alterado, otorgar al ciudadano el mismo nivel de protección que la garantía criminal proporciona frente a la imposición arbitraria de condenas. A la luz de estas consideraciones del TEDH, a priori pudiéramos responder que sí, en tanto pareciera que se atribuye a la garantía criminal los mismos elementos que en ordenamientos como el español, con el matiz de que la lex scripta y su consiguiente publicidad se suple con la noción de «previsibilidad» de la norma penal. El quid de la cuestión que se plantea reside en el modo de análisis que el TEDH va a utilizar para materializar la referida protección. ¿Qué criterios utiliza el TEDH para confirmar el carácter «previsible» del Derecho aplicado? ¿En qué posición coloca esta aproximación al ciudadano?

Adelantamos la respuesta: no hay una única aproximación a la noción de «previsibilidad», debiendo distinguir dos grandes posibilidades. Por un lado, encontramos una aproximación objetiva en la que se toma en consideración el contenido de la disposición legal aplicada, la labor de interpretación jurisprudencial que admitiría cierta «aclaración gradual» y, en ocasiones, la esencia del delito ${ }^{37}$; pero, de otro lado, y sobre todo cuando el TEDH se encuentra ante un déficit de fuentes formales para sustentar su toma de postura, distinguimos una aproximación subjetiva en la que el tribunal se introduce en la esfera de cognición del demandante para deslizar su razonamiento, pudiendo tener en cuenta «el número y estatus» de los destinatarios ${ }^{38}$.

Ya no responde a la pregunta de si el Derecho era previsible para un ciudadano medio, por el contrario, se pregunta si atendiendo a las circunstancias personales del sujeto este podía entender la ilicitud de su comportamiento y prever que daría lugar a responsabilidad penal ${ }^{39}$. Con otras

${ }^{37}$ Un ejemplo de aproximación objetiva a la noción de previsibilidad se observa en la STEDH de 20 de octubre de 2015 (Vasiliauskas v. Lithuania), donde el tribunal se sirvió de los textos internacionales y de la evolución jurisprudencial para negar que los grupos políticos o sociales quepan entre los grupos protegidos por el delito de genocidio, ver el comentario de J. Chinchón ÁlLVAREZ, «La Sentencia del Tribunal Europeo de Derechos Humanos en el caso Vasiliauskas c. Lituania (GS): el grupo protegido en el crimen de genocidio y su lesión en el marco del art. 7 del Convenio Europeo para la Protección de los Derechos y de las Libertades Fundamentales», REDI, vol. 68 (2016), pp. 239 y ss.

38 Por todas, STEDH 20 de octubre de 2015 (Vasiliauskas v. Lithuania), par. 156, «the scope of the concept of foreseeability depends to a considerable degree on the content of the instrument in issue, the field it is designed to cover and the number and status of those whom it is addressed».

39 G. VAnACore, «Legality, Culpability and Dogmatik: a Dialogue between the ECtHR, Comparative and International Criminal Law», International Criminal Law Review, vol. 15 
palabras, se trata de «la circunstancia de que los sujetos a los que se dirige el tipo tengan (o deban tener) un conocimiento específico de los riesgos inherentes al ejercicio de la actividad regulada (y sancionada) por la ley y estén en situación de distinguir entre los actos lícitos y los prohibidos» ${ }^{40}$. Veámoslo a través de dos ejemplos.

En el asunto Kononov c. Letonia, de 17 de mayo de 2010, la Gran Sala se plantea si: $i$ ) existía suficiente «base legal», teniendo en cuenta el estado del Derecho a 27 de mayo de 1944, para condenar al acusado por crímenes de guerra, y ii) si existiendo suficiente base legal, tales crímenes estaban definidos con suficiente accesibilidad y previsibilidad (par. 187) ${ }^{41}$. A la primera pregunta responde afirmativamente, señalando una serie de instrumentos de entre los que destaca la (IV) Convención de La Haya de 1907 relativa a las leyes y costumbres de la guerra terrestre ${ }^{42}$. Ahora bien, más difícil se presentaba la respuesta a la pregunta de si era «previsible» la condena por crímenes de guerra, en tanto que no había jurisprudencia en este sentido en la Unión Soviética (fuerza ocupante), ni las normas internacionales habían sido publicadas en Derecho interno ni recogidas en el Código Penal de 1926. Sin embargo, considera el TEDH que lo anterior no puede ser decisivo porque «las leyes y costumbres de la guerra en 1944 eran suficientes, por sí mismas, para dar lugar a responsabilidad penal individual» (par. 237), afirmando el carácter directamente aplicable (selfexecuting) de tales normas internacionales. En concreto, teniendo en cuenta la posición del autor como «commanding military officer» y la «flagrantly unlawful nature» del asesinato de nueve personas, entiende que la más fugaz reflexión del demandante habría indicado que tales comportamientos corrían el riesgo de ser contrarios a las leyes y costumbres de la guerra en 1944 (par. 238) ${ }^{43}$. De este modo, lo que debía ser un derecho subje-

(2015), p. 833, «it does not envisage deficiencies of the law in itself, examining violations of the non-retroactivity principle, of the probibition of contra reum interpretation by analogy or of the clarity, precision and specificity principle... the judges focus their attention on whether the individual could understand the illegality of his actions and could predict that these would be punishable».

${ }^{40}$ M. SCOLETTA, «El principio de legalidad europeo», op. cit., p. 270.

${ }^{41}$ STEDH de 17 de mayo de 2010 (Kononov v. Latvia), par. 187, añade «so the applicant could have known on 27 May 1944 what acts and omissions would make bim criminally liable for such crimes and regulated his conduct accordingly».

${ }^{42}$ En sentido crítico y al hilo de esta sentencia, T. MARINIELlo, «The "Nuremberg Clause" and Beyond», op. cit., p. 243, se pregunta «to what extent can an individual effectively predict that his conduct entails criminal consequences on the basis of a law constituting an obligation only for state?».

${ }^{43}$ STEDH de 17 de mayo de 2010 (Kononov v. Latvia), par. 238, por tanto «la visión 
tivo, que no subjetivado, a que se le aplique el Derecho vigente al tiempo de su comportamiento, siempre que este fuere razonablemente «previsible» y con toda la amplitud que el concepto de «Derecho» significa a la luz del Convenio, muta y parece responder a otra pregunta, esto es, hasta qué punto era «exigible» su conocimiento de la norma penal.

Otro caso conocido es el asunto Streletz, Kessler y Krenz c. Alemania, de 22 de marzo de 2001, relativo a tres altos cargos de la República Democrática Alemana (RDA) diseñadores de la práctica de disparos en el Muro de Berlín. Apoyándose en el propio ordenamiento de la RDA y en los compromisos internacionales de protección de derechos humanos que esta había adquirido, el TEDH considera que las normas que daban cobertura a la aberrante práctica no eran Derecho, sino violación del mismo (par. 88) ${ }^{44}$. Ahora bien, desde la perspectiva de la «previsibilidad» el tribunal pone el foco de atención en la posición ocupada por los acusados, haciendo hincapié en su participación en el aparato estatal, lo que les colocaba en una posición privilegiada para conocer la contradicción entre la práctica del Muro y las normas estatales y compromisos internacionales de la RDA, llegando a señalar que no podían «ignorar» tales normas ${ }^{45}$, término que también evoca aquí una sede distinta a la estricta legalidad penal.

Como señala Vanacore, pese al distinto tratamiento que recibe la ignorancia del Derecho en los ordenamientos continentales (eximente) y en los sistemas de common law (defense), y que trae su causa en las distintas concepciones del delito, lo cierto es que en ninguno de ellos la ignorancia sobre la ilicitud de la conducta se examina en sede de legalidad ${ }^{46}$. Por tanto, el origen de esta cuestionable subjetivación de la garantía criminal operada por el alto tribunal se podría encontrar: $i$ ) en la no «convenciona-

de la Corte es que habría sido razonablemente esperado que tomase especial cuidado en la evaluación de los riesgos de la operación en Mazie Bati».

${ }^{44}$ J. A. LASCURAÍn SÁNCHEZ, «La protección multinivel de la garantía de tipicidad penal», op. cit., p. 145, cree que afirmar que la conducta penada era contraria a las leyes de la $\mathrm{RDA}$ «es algo difícil de sostener desde una concepción del Derecho mínimamente holística y realista»; C. C. MuRPHY, «The principle of legality in criminal law under the ECHR», 2009, p. 5, cree que afirmar que tal práctica es violación del Derecho «is at odds with the Court's position in Kafkaris where it held that it "must have regard to the domestic law as a whole and the way it was applied at the material time"», European Human Rights Law Review, vol. 2 (2010) (trabajo disponible en https://papers.ssrn.com/sol3/papers.cfm?abstract_id=1513623, consultado el 3 de septiembre de 2018).

45 STEDH de 22 de marzo de 2001 (Streletz, Kessler and Krenz v. Germany), par. 78, «because of the very senior positions they occupied in the State apparatus, they evidently could not have been ignorant of the GDR's Constitution and legislations, or of its international obligations and the criticisms of its border-policing regime that had been made internationally».

${ }^{46}$ G. VANACORE, «Legality, Culpability and Dogmatik», op. cit., pp. 840 y ss. 
lización», o aun muy limitada, del principio de culpabilidad ${ }^{47}$, y ii) en el papel que juegan las fuentes no escritas en la compleja determinación del Derecho aplicable ${ }^{48}$, pues su aptitud tipificadora es limitada.

La búsqueda de un sustituto de la reserva de ley formal, y su consiguiente efecto de publicidad, nos parece loable siempre que su utilización esté reglada y ofrezca al acusado mayores garantías. En este sentido, compartimos que puede ofrecer grandes rendimientos una noción objetiva de «previsibilidad» que evalúe si el Derecho que se ha identificado como aplicable era previsible desde la perspectiva de un ciudadano medio. Sin embargo, la utilización de una aproximación subjetiva a este criterio parece ir en sentido contrario, sirviendo a la postre como último recurso o cajón de sastre ${ }^{49}$ para confirmar la compatibilidad de una condena con el art. 7 CEDH. Así entendido, sería una manera de ofrecer una aparente objetivación teórica al rechazable y excepcional argumento por el que un tribunal puede apoyar su decisión en la sola idea de justicia sustantiva.

Hasta ahora hemos señalado las dos causas principales de esta subjetivación y recordado algo que en nuestros ordenamientos internos estaría superado: no es lo mismo preguntarnos si el Derecho es «previsible» que si su conocimiento es «exigible», que es lo que sucede cuando en sede de legalidad se evalúa la «previsibilidad» subjetivamente. A los efectos de la justicia penal internacional, por la autoridad que reviste el TEDH y la ausencia de un sistema cerrado de Derecho internacional penal, en el examen del principio de legalidad se ha originado una recepción de las nociones de accesibilidad y previsibilidad, diálogo horizontal cuyos efectos se deben tomar con la prudencia propia al tratamiento de dos materias autónomas ${ }^{50}$.

${ }^{47}$ Sí ha habido algún paso para reconocer el principio de culpabilidad a la luz del art. 7 y evitar, en un futuro, tal solapamiento de razonamientos, pues como recuerda M. SCOLETTA, «El principio de legalidad europeo», op. cit., p. 272, «la estrechísima conexión entre principio de legalidad y principio de culpabilidad — a día de hoy no incluido en el catálogo de derechos fundamentales de la Unión Europea - ha sido por fin claramente establecido en la sentencia Sud Fondi c. Italia: el Tribunal, en esta decisión, ha reconocido de hecho que también forma parte del contenido sustancial del art. $7 \mathrm{CEDH}$ el «vínculo moral» entre el elemento material del delito y la persona autora de ese delito».

${ }^{48}$ H. VAN DER WILT, «Nullum Crimen and International Criminal Law: The Relevance of the Foreseeability Test», Nordic Journal of International Law, vol. 84 (3) (2015), p. 520 , «the need for foreseeability is particularly urgent if criminal responsibility is predicated on international (customary) law».

${ }^{49}$ J. García Roca, «El diálogo entre el Tribunal Europeo de Derechos Humanos, los Tribunales Constitucionales y otros órganos jurisdiccionales en el espacio convencional europeo», op. cit., p. 223.

50 T. Mariniello, P. Lobba, «Editorial. The Cross-fertilisation Rhetoric in Question: Use and Abuse of the European Court's Jurisprudence by International Criminal Tribunals», Nor- 
Los principales tribunales penales internacionales (TPIY y CPI) y las defensas van a tener la tentación de importar junto a la noción de «previsibilidad» su aproximación subjetiva. Fenómeno que nada tiene que ver con el hipotético desconocimiento científico de sus reputados miembros, sino y precisamente por la tensión entre unas fuentes, unos medios normativos, que no siempre van a ofrecer soluciones claras y la realización de una justicia que pasa por erradicar la impunidad. A continuación vamos a reseñar la práctica del TPIY y de la CPI, también mediante la selección de algunas resoluciones.

\section{LA IMPORTACIÓN DE LA «PREVISIBILIDAD» EN LA PRÁCTICA DE LOS PRINCIPALES TRIBUNALES INTERNACIONALES PENALES}

\section{La labor del Tribunal Penal Internacional para la antigua Yugoslavia (TPIY)}

Los traumáticos acontecimientos que se sucedieron en la antigua República de Yugoslavia tras el colapso del bloque soviético merecieron, entre otras respuestas, la creación de un tribunal internacional encargado de dirimir la responsabilidad de las principales violaciones del DIH desde 1991. El Consejo de Seguridad de Naciones Unidas (CSNU) en Resolución 808, de 22 de febrero de 1993, solicitó al Secretario General (SGNU) que emitiese un informe con todas las cuestiones relativas a dichos procedimientos que garantizasen un correcto funcionamiento del tribunal ${ }^{51}$. Sin duda, el

dic Journal of International Law, vol. 84 (3) (2015), p. 364, «the effective import of this intersystemic communication between the ECtHR and icts has been rarely put into question. This is in sharp contrast to other legal fields... As a consequence, methodologies and parameters to assess the reliance of icts on buman rights courts' jurisprudence are still uncertain. Indeed, the very notion of "fertilising" a different field, rather than a neutral designation, ascribes an immediately positive connotation to the process of transplantation. Still, this optimistic understanding seems to be grounded in prima facie sensible, though as yet unsupported and unverified, premises»; A. GIL GIL, «La fertilización cruzada entre las jurisprudencias de derechos humanos y de derecho penal internacional y el uso defectuoso de la jurisprudencia ajena», Revista de Derecho Penal, núm. extraordinario, 2012, pp. 112 y ss., concluye que bajo la fertilización cruzada «con frecuencia se esconde un uso interesado y parcial de la jurisprudencia ajena... y cuya finalidad en ocasiones es la de conseguir un castigo a toda costa, es decir, muchas veces a costa precisamente de derechos fundamentales y garantías básicas del derecho penal moderno».

${ }_{51}$ Resolución CSNU 808, de 22 de febrero de 1993, ONU Docs. S/RES/808 (1993). 
papel atribuido a este tribunal no era sencillo. El escaso y particular antecedente que constituían los tribunales militares posteriores a la Segunda Guerra Mundial y, en general, el limitado desarrollo del Derecho internacional penal, condicionaron su labor jurisdiccional, que al mismo tiempo, y pese a las propias vacilaciones, impulsó decididamente esta materia.

A los efectos del principio de legalidad, el SGNU señaló que «la aplicación del principio nullum crimen sine lege exige que el Tribunal Internacional aplique las normas del Derecho internacional humanitario que sin duda alguna forman parte del Derecho consuetudinario, de tal modo que no se plantee el problema de que algunos de los Estados, pero no todos, se hayan adherido a determinadas convenciones» ${ }^{52}$, de este modo «el Consejo de Seguridad no estaría creando normas de Derecho internacional ni tratando de "legislar"» (par. 29). No obstante, recuerda Olásolo que esta referencia ha dado lugar a vacilaciones jurisprudenciales en el recurso a los tratados internacionales como fuente del Derecho aplicable por este tribunal ${ }^{53}$.

Un ejemplo en el que la jurisprudencia acude a valoraciones ad extra del Derecho positivo, en los amplios términos en que aquí lo consideramos y precisamente a través de una aproximación subjetiva a la noción de «previsibilidad», es en la Decisión del Tribunal de Apelación resolviendo cuestión planteada por Ojdanic en el asunto Fiscalia c. Milutinovic, Sainovic y Ojdanic, de 21 de mayo de 2003, sobre la forma de responsabilidad penal individual, de construcción jurisprudencial, denominada «Joint Criminal Enterprise» (JCE). La defensa sostenía que no era un modo de responsabilidad expresamente previsto en el art. 7.1 ETPIY ni se identificaba su existencia en la voluntad de los redactores. El tribunal ya se había pronunciado en el asunto Tadic sobre esta forma de responsabilidad que identificaba no con la complicidad o colaboración, sino con la «comisión» prevista en el art. 7.1 en tanto exigía, además del acuerdo, la comisión de actos criminales en desarrollo del mismo ${ }^{54}$.

52 Informe presentado por el Secretario General de conformidad con el párrafo 2 de la Resolución 808 (1993) del Consejo de Seguridad, de 20 de mayo de 1993, ONU Docs. S/25704, par. 34.

53 H. Olásolo Alonso, «Del Estatuto de los Tribunales ad hoc al Estatuto de Roma de la Corte Penal Internacional: reflexiones sobre la evolución del principio nullum crimen sine lege en el Derecho penal internacional», Revista General de Derecho Penal, núm. 5 (2006), pp. 4 y ss.

54 A. GIL GIL, «Mens Rea in co-perpetration and indirect perpetration according to article 30 of the Rome Statute. Arguments against punishment for excesses committed by the agent or the co-perpetrator», International Criminal Law Review, vol. 14 (2014), p. 85, señala que la CPI ha rechazado la JCE, aunque más adelante también critica excesos a la luz de la teoría del dominio del hecho en los casos de coautoría y autoría mediata. 
De la Decisión se desprende que el principio de legalidad se aplica tanto a la definición de los crímenes como a otros elementos, como, por ejemplo, la señalada responsabilidad individual y sus formas. Para que se respete el principio de legalidad en una figura como la JCE, esta tiene que: $i)$ recogerse en el Estatuto de forma expresa o tácita; ii) contenerse en el Derecho internacional al tiempo de los hechos; iii) ser suficientemente accesible, y $i v$ ) ser suficientemente previsible para el autor. El TPIY se refiere aquí expresamente a la doctrina del TEDH y fertiliza su doctrina con la de aquel, al indicar que la satisfacción de la previsibilidad depende: i) del contenido del medio normativo; ii) del ámbito tutelado por la norma, y iii) del número y estatus de los destinatarios, aceptando así la aproximación objetiva y subjetiva.

En este sentido afirma que teniendo en cuenta el Derecho interno (art. 26 CP de Yugoslavia), el Derecho comparado, sentencias previas y la lesividad de la conducta, era previsible para el autor ser condenado por la «comisión» de la conducta y no como simple colaborador. Siendo inicialmente una aproximación objetiva al elemento «previsibilidad», el tribunal utiliza un criterio como es «the atrocious nature of the crimes charged». Aunque reconoce que no es un factor suficiente por sí solo para advertir su criminalización en Derecho internacional consuetudinario admite que «puede jugar de hecho un papel al respecto», y aquí está la aproximación subjetiva a la previsibilidad como criterio de evaluación de la garantía criminal, «insofar it may refute any claim by the Defence that it did not know of the criminal nature of the acts» (par. 42) $)^{55}$.

De nuevo, que la atrocidad que supone tal conducta sea suficiente para negar una posible ignorancia del Derecho y, consecuentemente, la valoración de «defences» como el error homónimo, puede ser una conclusión razonable pero no es lo que aquí se discute. Lo que aquí se trataba era de justificar el carácter objetivamente previsible de unas normas consuetudinarias, con mayor o menor apoyo en el Derecho vigente en la antigua Yugoslavia.

Del mismo modo que sucedía ante el TEDH, observamos cómo en este y otros casos, en que se produce la subjetivación de la garantía criminal y,

55 Decisión del Tribunal de Apelación resolviendo cuestión planteada por Ojdanic en el asunto Fiscalía c. Milutinovic, Sainovic y Ojdanic, de 21 de mayo de 2003, sobre la forma de responsabilidad penal individual, de construcción jurisprudencial, denominada «Joint Criminal Enterprise» (JCE), ONU Docs. IT-99-37-AR72, pars. 37 y ss., señalando más adelante que la suma de estos elementos «would have provided notice to anyone that the acts commited by the accused in 1999 would have engaged criminal responsability on the basis of participation in a joint criminal enterprise». 
en general, el recurso a valoraciones morales, tiene lugar cuando los hechos reclaman un reproche del que las fuentes formales no se han ocupado o, si lo han hecho, es difusamente a través de una práctica que en pocos casos podemos calificar como homogénea y generalizada. Detrás de estos casos se advierte no solo una cierta labor creadora o, al menos, de interpretación extensiva por parte del TPIY, sino también la recepción de un razonamiento que podría no estar valorando globalmente una definición de delito, y decimos «una» porque sigue abierta la cuestión a la luz de los textos internacionales en función de que se atribuya un mayor peso a la tradición del commom law o a la dogmática germana. Quizá a la luz de un instrumento de protección de derechos humanos como el CEDH tenga cabida, pero cuando lo que se dirime es la responsabilidad penal del individuo no es lo deseable.

\section{La labor de la Corte Penal Internacional (CPI)}

El Estatuto de la Corte Penal Internacional (ETPI) es el instrumento más desarrollado de la materia, aunque no llegue a ser una suerte de Código Penal mundial. Recoge en su art. 22 el principio nullum crimen sine lege y en el art. 24 la irretroactividad ratione personae ${ }^{56}$. Así, el art. 22 establece en el apartado primero la exigencia de una lex praevia de acuerdo con las fuentes formales recogidas en el art. 21, teniendo un papel principal el propio ECPI, los Elementos de los Crímenes y sus Reglas de Procedimiento y Prueba (art. 21.1). En el apartado segundo se recoge la interpretación estricta o, tal y como lo denominamos en España, el principio de tipicidad, así como la prohibición de aplicación analógica (lex stricta). Entendemos particularmente positiva la innovadora cláusula de su último inciso que traslada el principio in dubio pro reo al ámbito sustantivo. Y en el apartado tercero se precisa que el reconocimiento de este principio no afectará a otras conductas de Derecho internacional penal, es decir, las definiciones limitan sus efectos al ámbito del Estatuto ${ }^{57}$.

56 Una breve referencia a los trabajos del Comité Especial para el Establecimiento de un Tribunal Penal Internacional y de la Conferencia Diplomática de Roma se puede ver en S. LAMB, «Nullum crimen, nulla poena sine lege in International Criminal Law», en A. CASSESE, P. GAETA y J. Jones (eds.), The Rome Statute of the International Criminal Court: a commentary, vol. I, Oxford, Oxford University Press, 2002, p. 746, señalando que en ellos «the need to guarantee the certainty of law through the principle of nullum crimen sine lege appeared to be undisputed》.

57 W. A. SCHABAS, The International Criminal Court. A commentary of the Rome Statute, Oxford, Oxford University Press, 2010, p. 411: «Outside of the context of the International 
Por su parte, aunque la noción de garantía criminal bajo el aforismo nullum crimen sine lege se regula separadamente del principio de irretroactividad, lo cierto es que su contenido es complementario, pudiendo distinguir en la operación de interpretación dos momentos sucesivos. Así, en primer lugar, se trata de que el tribunal identifique la norma que criminaliza la conducta y, en un segundo estadio, hay que determinar a partir de qué momento entró en vigor para concretar a qué hechos, en una línea temporal, se puede aplicar dicha norma. Por su parte, en el segundo apartado del art. 24 se recoge la lex mitior o aplicación retroactiva de las normas favorables antes de que se dicte la sentencia definitiva, de manera que no será revisable la condena una vez pronunciada.

Teniendo en cuenta que el ECPI recoge un subsistema de fuentes formales donde tienen un mayor peso las normas escritas, una regulación más estricta de la garantía criminal y el reconocimiento de unos principios generales a modo de parte general donde se regula el error de Derecho, con toda la problemática interpretativa que ello suscita ${ }^{58}$, se puede observar que la recepción de la noción de «previsibilidad» se está llevando a cabo desde una aproximación objetiva. Veámoslo a través de dos ejemplos.

En este sentido, debemos referirnos a la Decisión de confirmación de los cargos en el asunto Fiscalía c. Lubanga, de 29 de enero de $2007^{59}$. En ella se afirma que la defensa cree que el crimen de utilizar a menores de quince años para participar en acciones hostiles no era previsible para Lubanga. El tribunal, a diferencia de lo que ha ocurrido en algunos casos ante la CEDH o ante el TPIY, distingue entre el principio de legalidad y error de Derecho. En un primer momento, frente a lo que sostiene la defensa, justifica la criminalización de tal comportamiento en el ECPI y en los Elementos de los Crímenes. De manera que si se decide condenar a Lubanga no habría «infracción del principio de legalidad» ${ }^{60}$.

Criminal Court, article 22 cannot be invoked in a claim that acts are not international crimes due to their omission in the Rome Statute. For example, the international crime of inchoate conspiracy to commit genocide, which is defined in the 1948 Genocide Convention as well as in the statutes of the ad hoc tribunal... but which is not incorporated in the Rome Statute, remains criminal under the law of nations».

58 Sobre el debate doctrinal vid. M. MELENDO PARDOs, Imputación subjetiva y error en el Estatuto de la Corte Penal Internacional. Desafíos para la dogmática penal continental, Barcelona, Atelier, 2008.

59 Decisión de confirmación de cargos de la Sala de Primera Instancia en el asunto Fiscalía c. Lubanga, de 29 de enero de 2007.

${ }^{60}$ A ello se refiere W. A. ScHABAS, The International Criminal Court, op. cit., p. 408, citando el párrafo 303 donde se esboza la postura de la Corte sobre el contenido de esta 
Por tanto, se tratar de respetar la accesibilidad a la norma y la previsibilidad como requisitos también mencionados tanto por la defensa como por la Fiscalía.

Ahora bien, cuestión distinta es si Lubanga había errado sobre la ilicitud del crimen consistente en reclutar a menores de quince años. La CPI, en vez de considerar que seguimos en el ámbito de la legalidad penal, reconoce que lo que la defensa pretende es justificar la existencia de un error de Derecho, esto es, que el autor desconocía la ilicitud del hecho antijurídico, que su conducta violaba el ordenamiento internacional. Y para dar respuesta a este argumento, el tribunal recuerda: $i$ ) que la República Democrática del Congo (RDC) había ratificado el ECPI, que entró en vigor el 11 de abril de 2002; ii) que los niños menores de quince años deben ser considerados personas protegidas a los efectos de los Convenios de Ginebra de 1949 y de los dos PA de 1977, refiriéndose en particular al art. 77.2 PA II, todos ratificados por la RDC; iii) que la protección de los niños en DIH está reconocida en la Convención de los Derechos del Niño de 1989; iv) que la Sala de Apelaciones de la Corte Especial para Sierra Leona había declarado que tal prohibición de reclutar a niños menores de quince años era costumbre internacional en 1966; $v$ ) que las comunidades Hema y Lendu de Ituri estaban familiarizadas con el ECPI y con los tipos de confuctas que daban lugar a responsabilidad internacional en el ECPI, y vi) que Kristine Peduto (miembro de Unicef) había conversado en mayo de 2003 con Lubanga, precisamente, sobre la protección de los niños tras la aprobación del Estatuto de Roma (pars. 307-313). Es por ello que el tribunal entiende que Lubanga era consciente de que sus comportamientos eran contrarios al Derecho vigente y, por tanto, no puede aplicar el error de Derecho regulado en el art. 32.2.

Esta decisión, más allá de la debatible calificación del reclutamiento de menores de quince años como costumbre internacional, aporta una precisa distinción entre el análisis de la garantía criminal y su requisito de previsibilidad (objetiva), por un lado, y el error de Derecho.

Interesa señalar que, tras la Decisión confirmatoria de los cargos de la CPI en el asunto Fiscalía c. Ngudjolo, la jueza Christine Van den Wyngaert

garantía en los siguientes términos: «there is no infringement of the principle of legality if the Chamber exercises its power to decide whether Thomas Lubanga Dyilo ought to be committed for trial on the basis of written (lex scripta) pre-existing criminal norms approved by the States Parties to the Rome Statute (lex praevia), defining probibited conduct and setting out the related sentence (lex certa), which cannot be interpreted by analogy in malam partem (lex stricta)». 
presentó un voto particular, de 18 de diciembre de 2012, en el que expresa unas consideraciones sobre la responsabilidad penal individual y la construcción desarrollada por la Corte, en tanto contraria al principio de legalidad. Así, la Corte utiliza en sus fundamentos la doctrina del dominio sobre el hecho y reconoce la denominada «coautoría indirecta» como una cuarta forma de comisión material propia del art. 25.3.a) para condenar a aquellos líderes que idearon una determinada práctica.

Como respuesta, la jueza recuerda: i) que en cuanto a las fuentes, la costumbre tiene un papel más limitado en el ECPI que en los tribunales ad hoc; ii) que el propio ECPI no ha recogido en el art. 25.3 términos como «planear» que serían más adecuados para condenar a los diseñadores de una práctica criminal; iii) que la teoría del dominio sobre el hecho no es universalmente aceptada y que difícilmente se puede considerar un principio general del Derecho; $i v$ ) que el principio de legalidad no solo se aplica a las definiciones de los crímenes, sino también a aspectos como la responsabilidad individual, y $v$ ) que la doctrina de la accesibilidad y previsibilidad no sería respetada, porque la teoría de la coautoría indirecta es ajena al sistema judicial de muchos de los destinatarios de la misma, precisamente porque es una construcción que no se encuentra generalmente observada en la práctica estatal ni en la jurisprudencia internacional, no siendo previsible objetivamente una condena en virtud de la misma ${ }^{61}$.

En definitiva, desde la perspectiva de la legalidad penal, creemos que la línea sostenida en estos dos pronunciamientos (decisión y voto particular), más allá de la concreta solución a que se ha llegado, establece el método que debe ser seguido en la interpretación de la «previsibilidad» si se quiere introducir como elemento de la garantía criminal.

\section{CONCLUSIONES}

La primera idea que se ha tratado de explicar en las anteriores líneas es el motivo por el que no es exactamente extrapolable la noción de garantía criminal como una de las manifestaciones del principio de legalidad al ordenamiento internacional: la ausencia de una reserva de ley formal. En los ordenamientos continentales, donde originariamente se ha desarrolla-

${ }^{61}$ Voto particular de la jueza Christine Van den Wyngaert en el asunto Fiscalía c. Ngudjolo, de 18 de diciembre de 2012, par. 8-22. 
do el principio de legalidad, se ha entendido que el ius puniendi merece ser regulado exclusivamente por el legislador, solo él está autorizado para elaborar normas que constriñan de forma tan importante una libertad individual que debe ser maximizada. Frente a ello, el ordenamiento internacional, donde ya no es el individuo sino el Estado el sujeto por excelencia, admite una pluralidad de medios normativos que abarcan tanto formas escritas como no escritas. Se trata, por tanto, de un cambio de presupuesto en la pretensión de materializar una garantía criminal que ahora podrá merecer otras construcciones.

A esta tarea ha parecido encomendarse el TEDH y en su búsqueda ha encontrado un sustituto para la reserva de ley formal: la previsibilidad. Con esta noción se trata de suplir aquel presupuesto de la garantía criminal, especialmente al ofrecer un contenido similar a la nacional idea de publicidad. El problema aquí abordado se origina cuando, precisamente para justificar la conformidad de una condena con el principio de legalidad penal reconocido en el art. 7 CEDH, apoya su confirmación de la existencia de un Derecho aplicable al asunto, con unas determinadas características limitadoras de la arbitrariedad, en el estatus y la noción que el propio sujeto pueda tener del carácter antijurídico de su conducta. Es decir, el razonamiento garantista por el cual se exige que el Derecho sea «previsible» muta y parece responder a otra pregunta, esto es, hasta qué punto era «exigible» que dicho ciudadano conociese que su conducta vulneraba el ordenamiento internacional.

Siendo este un razonamiento que a la luz del CEDH pudiera admitirse, en tanto el principio de culpabilidad no está plenamente convencionalizado y el sistema de fuentes formales impulsa la búsqueda de nuevos modos de respetar formal y materialmente la garantía criminal, sin embargo, esto no nos parece asumible en el ámbito penal. Con todo, y precisamente por la mencionada amplitud de medios normativos, los tribunales penales internacionales y los operadores jurídicos que en ellos han intervenido no han desconocido esta tentación que el TEDH puso a su disposición, ahora bien, con resultados diferentes.

Mientras en el ámbito del TPIY sí encontramos ejemplos de esta aproximación subjetiva a la noción de «previsibilidad» para confirmar la existencia de una norma penal y, por ende, el respeto al principio de legalidad en la labor de atribución de responsabilidad individual, la CPI parece no haber admitido este modo de razonar. Ello no significa que siempre se vaya a respetar el principio de legalidad, pero al menos este fenómeno que rechazamos, no así la noción objetiva de «previsibilidad», 
podría ir cayendo en desuso. Entendemos que para la construcción de un Derecho internacional penal cohesionado es necesario que en sede de legalidad, en sede de un derecho subjetivo, el enfoque del análisis mantenga el criterio del ciudadano medio y ponga el foco de atención exclusivamente en el Derecho presuntamente aplicable, sea cual fuere la amplitud que se le atribuya.

\section{BIBLIOGRAFÍA CITADA}

Álvarez García, F. J.: Sobre el principio de legalidad, Valencia, Tirant lo Blanch, 2009.

Ambos, K.: «La construcción de una parte general del Derecho penal internacional», Revista Penal, núm. 17 (2006), pp. 5-33.

Bassiouni, M. C.: Introduction to International Criminal Law, 2. ${ }^{a}$ ed., Boston, Martinus Nijhoff Publishers, 2014.

BoHLANDER, M.: «Volver a Radbruch. La necesidad de retomar de raíz el diálogo entre common law y Derecho continental, en atención al ejemplo de la justicia penal internacional», en E. FerRer MAC-Gregor y A. HerRera GARCíA (coords.), Diálogo jurisprudencial en derechos bumanos entre Tribunales Constitucionales y Cortes Internacionales, Valencia, Tirant lo Blanch, 2013, pp. 1119-1146.

Carbonell Mateu, J. C.: Derecho penal: concepto y principios constitucionales, 2. ${ }^{a}$ ed., Valencia, Tirant lo Blanch, 1996.

Carrillo Salcedo, J. A.: El Convenio Europeo de Derechos Humanos, Madrid, Tecnos, 2003.

Casadevall, J.: El Convenio Europeo de Derechos Humanos, el Tribunal de Estrasburgo y su Jurisprudencia, Valencia, Tirant lo Blanch, 2012.

Cassese, A.: «Balancing the Prosecution of Crimes Against Humanity and Nonretroactivity of Criminal Law. The Kolk and Kislyiy v. Estonia Case before the ECHR», Journal of International Criminal Justice, vol. 4 (2006), pp. 410-418.

- International Criminal Law, 3. ed., Oxford, Oxford University Press, 2013.

Castillo Daudí, M., y Salinas Alcega, S.: Responsabilidad penal del individuo ante los tribunales internacionales, Valencia, Tirant lo Blanch, 2007.

CHINCHÓN Álvarez, J.: «La responsabilidad internacional penal del individuo: un gigante con pies de barro», Revista de Ciencias Jurídicas, núm. 108 (2005), pp. 31-60.

- Derecho Internacional y Transiciones a la Democracia, Sevilla, Parthenon, 2007.

- «La Sentencia del Tribunal Europeo de Derechos Humanos en el caso Vasiliauskas c. Lituania (GS): el grupo protegido en el crimen de genocidio y su 
lesión en el marco del art. 7 del Convenio Europeo para la Protección de los Derechos y de las Libertades Fundamentales», Revista Española de Derecho Internacional, vol. 68 (2016), pp. 239-243.

D'Ascoli, S.: Sentencing in International Criminal Law. The UN ad hoc Tribunals and Future Perspectives for the ICC, Oxford, Hart Publishing, 2011.

De Vicente Martínez, R.: El principio de legalidad penal, Valencia, Tirant lo Blanch, 2004.

García de Enterría, E.: «El principio de legalidad, estado material de Derecho y facultades interpretativas y constructivas de la jurisprudencia en la Constitución», Revista Española de Derecho Constitucional, núm. 10 (1984), pp. 11-62.

- La lengua de los derechos. La formación del Derecho público europeo tras la Revolución francesa, Madrid, Alianza Universidad, 1994.

García Roca, J.: «El diálogo entre el Tribunal Europeo de Derechos Humanos, los Tribunales Constitucionales y otros órganos jurisdiccionales en el espacio convencional europeo», en E. FerRer MAC-Gregor y A. HerRera GarCía (coords.), Diálogo jurisprudencial en derechos bumanos entre tribunales constitucionales y cortes internacionales, Valencia, Tirant lo Blanch, 2013, pp. 219-242.

GIL GIL, A.: «La excepción al principio de legalidad del número 2 del artículo 7 del Convenio Europeo de Derechos Humanos», Anuario de Derecho Penal y Ciencias Penales, vol. 63 (2010), pp. 131-164.

- «La fertilización cruzada entre las jurisprudencias de derechos humanos y de Derecho penal internacional y el uso defectuoso de la jurisprudencia ajena», Revista de Derecho Penal, núm. extraordinario (2012), pp. 111 y ss.

- «Mens Rea in Co-Perpetration and Indirect Perpetration According to Article 30 of the Rome Statute. Arguments Against Punishment for Excesses Committed by the Agent or the Co-Perpetrator», International Criminal Law Review, vol. 14 (2014), pp. 82-114.

GonZÁlez Aguadelo, G.: «El principio de reserva de ley penal y las leyes penales en blanco. Una reflexión sobre el derecho fundamental a la legalidad penal», Revista General de Derecho Penal, núm. 28 (2017).

Grover, L.: «A Call to Arms: Fundamental Dilemmas Confronting the Interpretation of Crimes in the Rome Statute of the International Criminal Court», The European Journal of International Law, vol. 21 (3) (2010), pp. 543-583.

Huerta TOCILDO, S.: «El derecho fundamental a la legalidad penal», Revista Española de Derecho Constitucional, núm. 39 (1993), pp. 81-114.

- «El contenido debilitado del principio europeo de legalidad penal (art. 7 CEDH y art. 4 P7)», en J. García Roca y P. SANTOLAYA (coords.), La Europa de los Derechos: el Convenio Europeo de Derechos Humanos, Madrid, Centro de Estudios Políticos y Constitucionales, 2009, pp. 511-543.

Lamarca Pérez, C.: «Legalidad penal y reserva de ley en la Constitución española», Revista Española de Derecho Constitucional, núm. 20 (1987), pp. 99-138.

— «Principio de legalidad penal», Eunomía, núm. 1 (2011), pp. 156-160. 
LAMB, S.: «Nullum crimen, nulla poena sine lege in International Criminal Law», en A. Cassese, P. Gaeta y J. Jones (eds.), The Rome Statute of the International Criminal Court: A Commentary, vol. I, Oxford, Oxford University Press, 2002.

Lascuraín SÁnchez, J. A.: «La protección multinivel de la garantía de tipicidad penal», en M. Pérez Manzano y J. A. Lascuraín SÁnchez (coords.), La tutela multinivel del principio de legalidad penal, Madrid, Marcial Pons, 2016, pp. 119-148.

Malarino, E.: «Activismo judicial, punitivización y nacionalización. Tendencias antidemocráticas y antiliberales de la Corte Interamericana de Derechos Humanos», en K. Ambos, G. Elsner y E. Malarino (coords.), Sistema Interamericano de protección de los derechos bumanos y derecho penal internacional, vol. I, Montevideo, Fundación Konrad-Adenauer, 2010, pp. 25-62.

Mariniello, T.: «The "Nuremberg Clause" and Beyond: Legality Principle and Sources of International Criminal Law in the European Court's Jurisprudence», Nordic Journal of International Law, vol. 82 (2) (2013), pp. 221-248.

Mariniello, T., y Lobba, P.: «Editorial. The Cross-Fertilisation Rhetoric in Question: Use and Abuse of the European Court's Jurisprudence by International Criminal Tribunals», Nordic Journal of International Law, vol. 84 (3) (2015), pp. 363-369.

Melendo Pardos, M.: Imputación subjetiva y error en el Estatuto de la Corte Penal Internacional. Desafíos para la dogmática penal continental, Barcelona, Atelier, 2008.

Murphy, C. C.: «The Principle of Legality in Criminal Law under the ECHR», European Human Rights Law Review, vol. 2 (2010), disponible en bttps:// papers.ssm.com/sol3/papers.cfm?abstract_id=1513623 (consultado el 3 de septiembre de 2018).

Olásolo Alonso, H.: «Del Estatuto de los Tribunales ad hoc al Estatuto de Roma de la Corte Penal Internacional: reflexiones sobre la evolución del principio nullum crimen sine lege en el Derecho penal internacional», Revista General de Derecho Penal, núm. 5 (2006).

- Introducción al Derecho Internacional penal, Valencia, Tirant lo Blanch, 2015.

Pérez-Prat Durbán, L.: «La responsabilidad internacional, ¿crímenes de Estados y/o de individuos?», Anuario de la Facultad de Derecho de la Universidad Autónoma de Madrid, núm. 4 (2000), pp. 205-248.

RAUTER, T.: Judicial Practice, Customary International Criminal Law and Nullum Crimen Sine Lege, Salzburg, Springer, 2017.

Schabas, W.: «Article 21. Applicable Law», en The International Criminal Court: A commentary on the Rome Statute, Oxford, Oxford University Press, 2010.

Scoletta, M.: «El principio de legalidad europeo», en L. Díez-Picazo y A. Nieto Martín (coords.), Derechos fundamentales en el Derecho penal europeo, Madrid, Civitas, 2010, pp. 251-304.

Tiedemann, K.: «Constitución y Derecho penal [Traducción: Luís Arroyo Zapatero]», Revista Española de Derecho Constitucional, núm. 33 (1991), pp. 145-174. 
Timmerman, M.: Legality in Europe. On the principe nullum crimen, nulla poena sine lege in EU law and under the ECHR, Cambridge, Intersentia, 2018.

VAN DER WILT, H.: «Nullum Crimen and International Criminal Law: The Relevance of the Foreseeability Test», Nordic Journal of International Law, vol. 84 (3) (2015), pp. 515-531.

Vanacore, G.: «Legality, Culpability and Dogmatik: a Dialogue between the ECTHR, Comparative and International Criminal Law», International Criminal Law Review, vol. 15 (5) (2015), pp. 823-860. 